\title{
INHIBITION OF GLUCAGON AND INSULIN RELEASE FROM THE ISOLATED PERFUSED RAT PANCREAS BY CALMODULIN INHIBITORS
}

\author{
KEN YAGA, AKIRA MATSUTANI, YASUSHI INOUE, KATSUMASA KOBAYASHI and \\ TOSHIO KANEKO
}

The Third Department of Internal Medicine, Yamaguchi University School of Medicine, Ube 755, Japan

\begin{abstract}
Effects of $N$-(6-aminohexyl)-5-chloro-1-naphthalenesulfonamide (W-7) and trifluoperazine, specific calmodulin inhibitors, on the glucose-induced insulin release and arginine-induced glucagon release from the isolated perfused rat pancreas were studied. These two drugs at $50 \mu \mathrm{M}$ significantly suppressed the insulin release in both the first and second phases. The extent of suppression was less with W-7 than with trifluoperazine at equivalent concentrations. Trifluoperazine at $50 \mu \mathrm{M}$ reduced the efflux rate to $25 \%$ of the initial level, but the available data indicate that the reduction in the insulin release by trifluoperazine is attributable to a direct action of this agent on B cells. Suppression of insulin release by W-7 was initiated within 1 min after introducing the agent into the perfusion medium; withdrawal of W-7 caused an immediate over-secretion of insulin in response to glucose. Arginine-induced glucagon release from the perfused pancreas was also inhibited by trifluoperazine at $25 \mu \mathrm{M}$ and $50 \mu \mathrm{M}$; with W-7, however, glucagon release was inhibited only at a higher concentration $(100 \mu \mathrm{M})$. These results suggest that calmodulin is involved in the process of insulin release as well as glucagon release from the pancreas.
\end{abstract}

KEY WORDS calmodulin / calmodulin inhibitor / W-7 / trifluoperazine / insulin release / glucagon release

$\mathrm{Ca}^{2+}$ has been implicated as a fundamental regulator in a variety of cellular function including secretion, and the possibility that $\mathrm{Ca}^{2+}$ may act through its binding to the specific protein was suggested by Meyer et al. (12) in 1964.

Following the discovery of calmodulin by Kakiuchi et al. (6) and Cheung (1) as a heatstable protein activator of brain cyclic nucleotide phosphodiesterase, a wide distribution of this Ca-binding protein has been demonstrated throughout the animal and plant kingdom including rat islets of Langerhans (17, $18)$.

In isolated islets of rats, calmodulin has been reported to stimulate the activity of phosphodiesterase (17), adenylate cyclase $(16,18)$ and
$\mathrm{Ca}^{2+}$-ATPase (14). Experiments on isolated islets of rat using a specific calmodulin inhibitor such as trifluoperazine $(8,15,17)$ suggested a possible important role of calmodulin in $\mathrm{Ca}^{2+}$. dependent insulin release. Recently, Hidaka et al. $(4,5,7)$ described a new calmodulin inhibitor, $N$-(6-Aminohexyl)-5-chloro-1-naphthalenesulfonamide (W-7), which is chemically different from phenothiazine derivatives.

Based on these lines of information we undertook to examine the role of calmodulin in endocrine pancreas, taking advantage of these calmodulin inhibitors. W-7 and trifluoperazine proved to inhibit not only the insulin release but also glucagon release from the isolated perfused pancreas of rats. 


\section{MATERALS AND METHODS}

The pancreas with the proximal portion of the duodenum was isolated from the Wistar male rat weighing $250-350 \mathrm{~g}$ after an overnight fast, by the method of Grodsky et al. (3), with modifications. The basal perfusion medium was Krebs-Ringer bicarbonate buffer ( $\mathrm{pH} 7.4$ ) containing $4.5 \%$ dextran $\mathrm{T}-70,0.5 \%$ bovine serum albumin and $2.5 \mathrm{mM}$ glucose, and continuously gassed with $95 \% \mathrm{O}_{2}-5 \% \mathrm{CO}_{2}$. The perfusion medium was introduced into the celiac artery at a flow rate of $2.5-3.5 \mathrm{ml} / \mathrm{min}$ during the equilibration period of $30 \mathrm{~min}$. Secretagogue used was $10 \mathrm{mM}$ D-glucose for insulin, and $15 \mathrm{mM}$ L-arginine for glucagon. Calmodulin inhibitor was introduced $5 \mathrm{~min}$ before the secretagogue. The effluent was separately collected every minute from the portal vein after a single passage through the pancreas. Insulin and glucagon in the perfusate were assayed by radioimmunoassay.

$\mathrm{N}$-(6-Aminohexyl)-5-chloro-1-naphthalenesulfonamide (W-7) was a generous gift from Drs H. Hidaka and N. Aoki. Trifluoperazine dimalate was obtained from Yoshitomi Pharmaceutical Co.
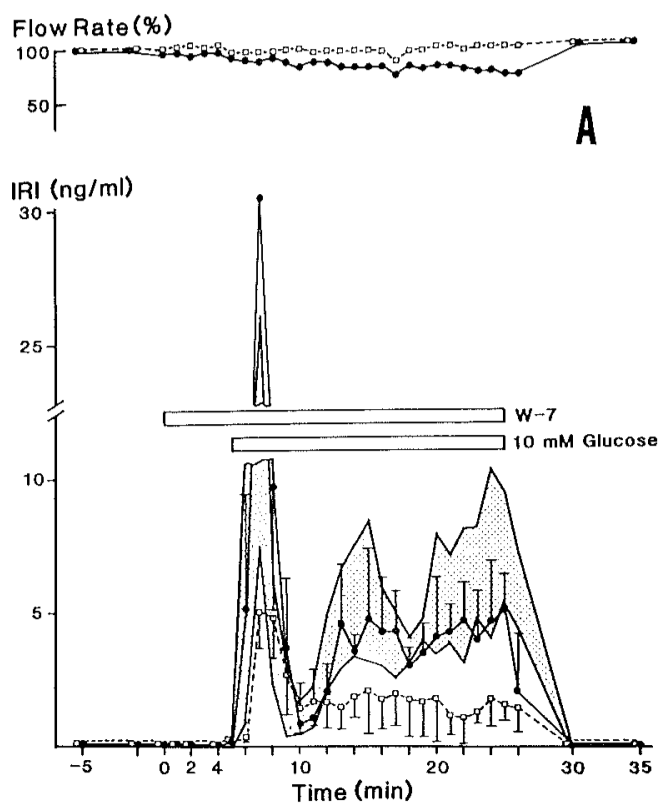

\section{RESULTS}

Effects of W-7 and trifluoperazine on the insulin release induced by $10 \mathrm{mM}$ glucose are shown in Fig. 1, A and B. Both W-7 and trifluoperazine did not affect the basal release of insulin from the pancreas. W-7 at $25 \mu \mathrm{M}$ had no apparent effect on glucose-induced insulin release, but trifluoperazine at the same concentration markedly inhibited the release. W7 at $50 \mu \mathrm{M}$ significantly inhibited the glucoseinduced insulin release, but the extent of inhibition was less than with $50 \mu \mathrm{M}$ trifluoperazine.

When the experiment was done under a constant perfusion pressure, trifluoperazine caused a marked reduction in the efflux rate, and the rate was not restored even when the pressure was raised. This effect of trifluoperazine was dose-dependent.

The inhibitory effects of W-7 and trifluoperazine on the first and second phases of glucoseinduced insulin release from the pancreas are summarized in Fig. 2, A and B. In the presence of $25 \mu \mathrm{M}$ trifluoperazine, the amount of insulin released in response to glucose was reduced by $75 \%$ in the first phase $(0-4 \mathrm{~min})$, by $85 \%$ in the second phase $(5-20 \mathrm{~min})$, and by $80 \%$ during the total period of the drug admin-
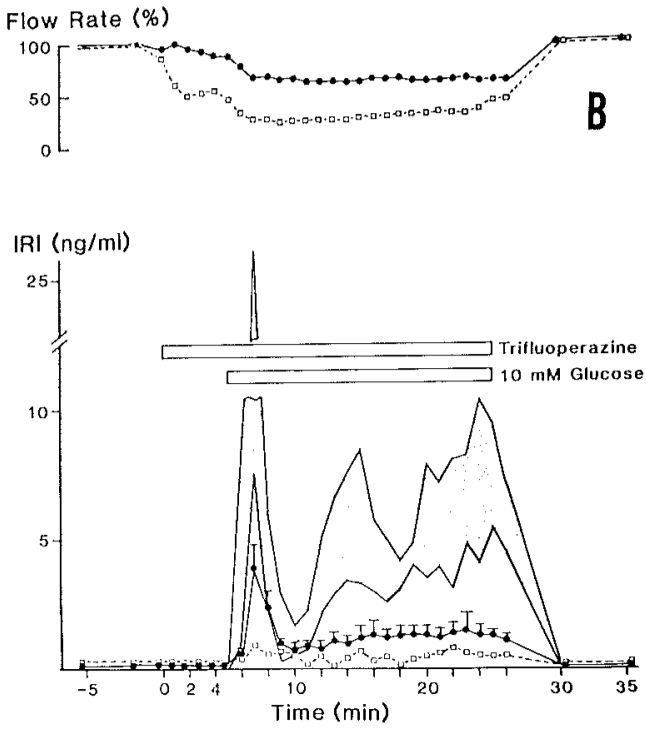

Fig. 1 Effects of W-7 and trifluoperazine on the insulin release from the isolated perfused rat pancreas. Insulin release was induced by $10 \mathrm{mM}$ D-glucose. A: W-7; and B: trifluoperazine. $-\mathbf{-}-25 \mu \mathrm{M}$; and $\square-\cdots, 50 \mu \mathrm{M}$. Values are means $\pm \mathrm{SD}$ (vertical bars). Values (means $\pm \mathrm{SD}$ ) in control experiments are shown by the shaded area. 

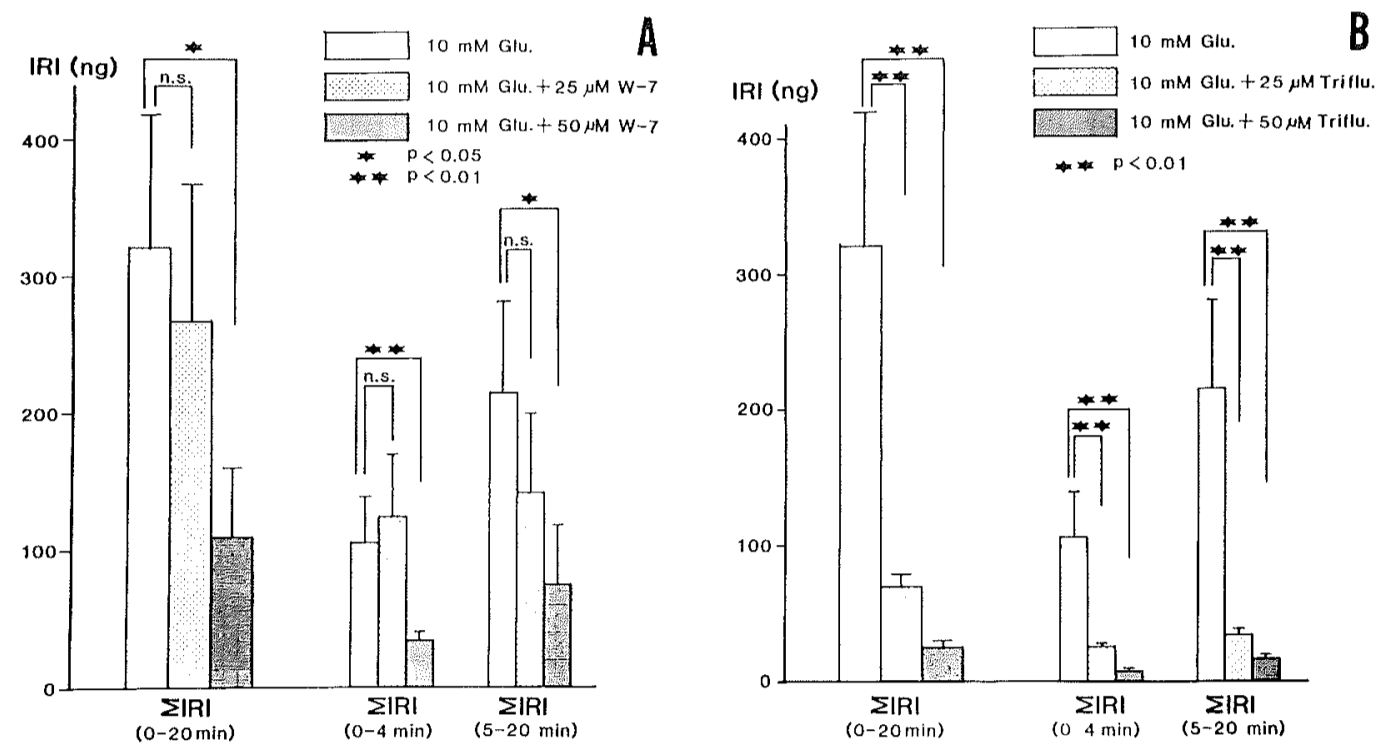

Fig. 2 Inhibition of glucose-induced insulin release by W-7 (A) and trifluoperazine (B). Total amounts of insulin that were released during the total period $(0-20 \mathrm{~min})$, the first phase $(0-4 \mathrm{~min})$ and the second phase $(5-20 \mathrm{~min})$ are separately shown. Statistical significance of differences between various conditions indicated were analyzed by the Student $t$-test. ${ }^{*} P<0.05 ;$ and ${ }^{* *} P<0.01$

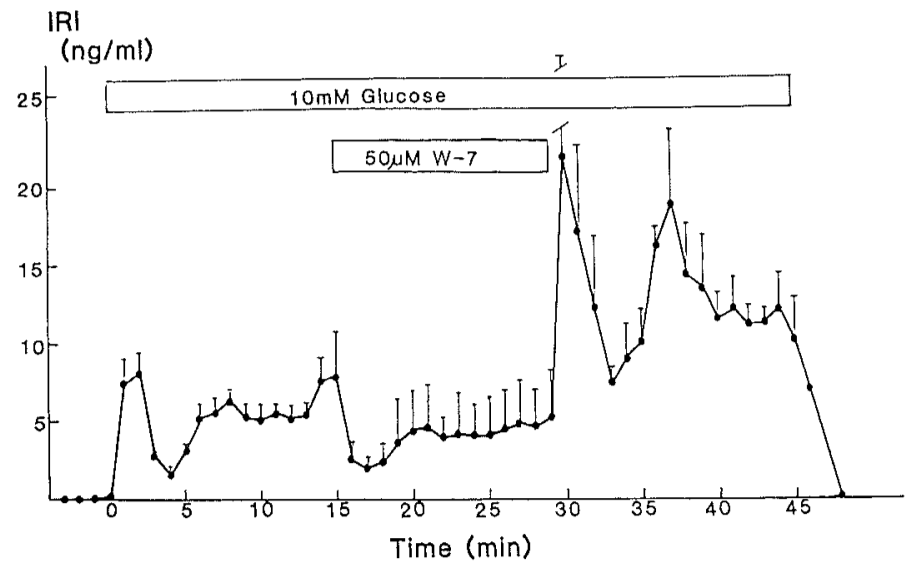

Fig. 3 Time course of insulin release affected by W-7. The pancreas was perfused with $10 \mathrm{mM}$ D-glucose for the initial $15 \mathrm{~min}$, with glucose and $50 \mu \mathrm{M} \mathrm{W}-7$ for the following $15 \mathrm{~min}$, and again only with glucose thereafter. Values are means $\pm \mathrm{SD}$ (vertical bars).

istration $(0-20 \mathrm{~min})$. W-7 and trifluoperazine at $50 \mu \mathrm{M}$ inhibited the total release of insulin by $65 \%$ and $90 \%$, respectively.

Fig. 3 shows the time course of inhibition of insulin release caused by $50 \mu \mathrm{M} \mathrm{W}-7$. The pancreas was perfused with $10 \mathrm{mM}$ glucose for 15 min, with glucose plus $50 \mu \mathrm{M} \mathrm{W}-7$ for the next $15 \mathrm{~min}$, and again only with glucose for the final $15 \mathrm{~min}$. Insulin release was inhibited by $\mathrm{W}-7$ within $1 \mathrm{~min}$. Within $1 \mathrm{~min}$ following the withdrawal of $W-7$, the amount of insulin released in the perfusate was abruptly increased to an extraordinarily high level.

The effects of W-7 and trifluoperazine on arginine-induced glucagon release are shown in Fig. 4, A and B. W-7 at $25 \mu \mathrm{M}$ and $50 \mu \mathrm{M}$ did not inhibit arginine-induced glucagon release, except for a marginal decrease in glucagon release observed $2 \mathrm{~min}$ after the introduction of W-7. However, W-7 at a higher concentration $(100 \mu \mathrm{M})$ strongly inhibited the glucagon release. Following the withdrawal of 

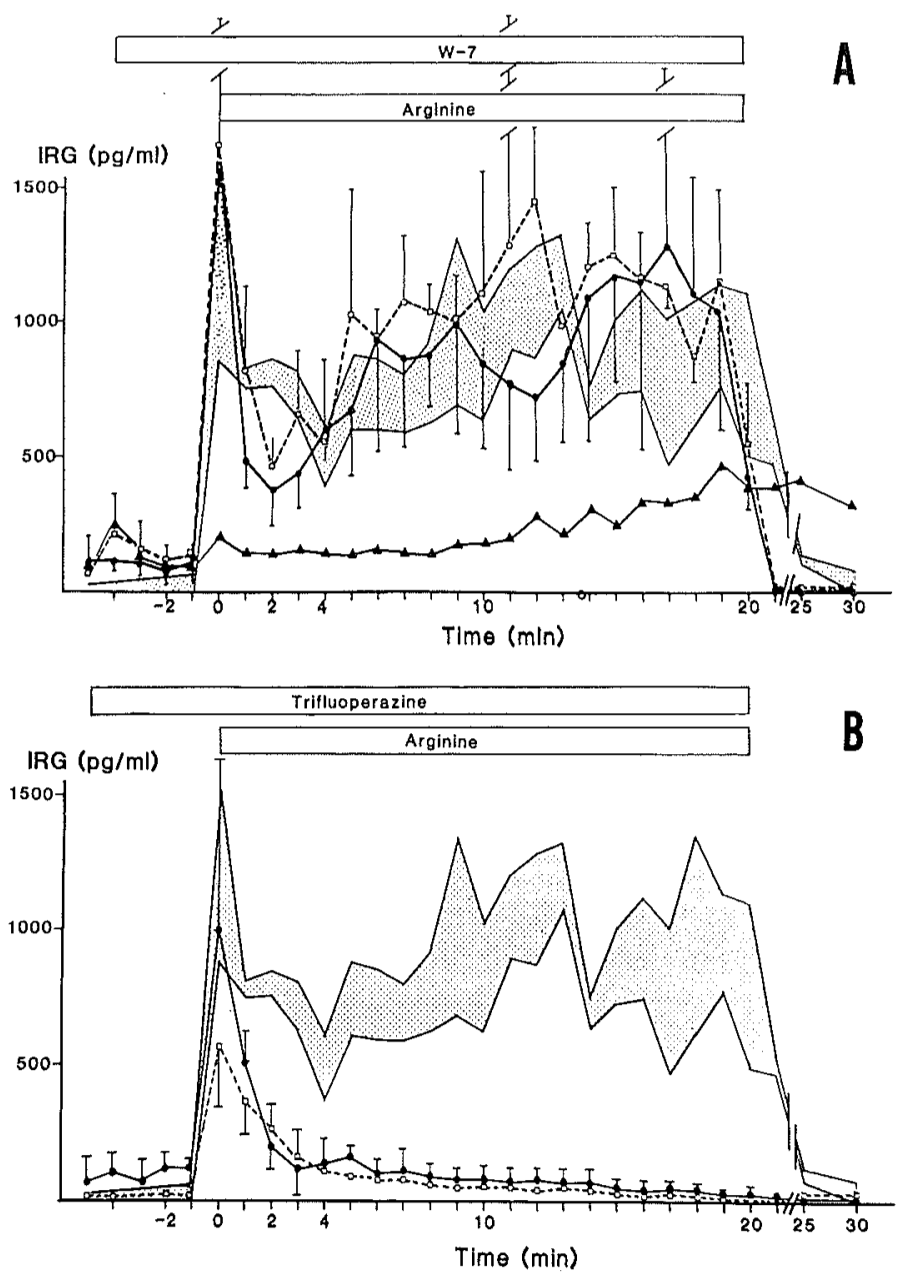

Fig. 4 Effects of $W-7$ and trifluoperazine on the glucagon release from the isolated perfused rat pancreas. Glucagon release was induced by $15 \mathrm{mM}$ L-arginine. $\mathrm{A}$ : W-7; and $\mathrm{B}$ : trifluoperazine. $-\infty, 25$ $\mu \mathrm{M} ; \square-\cdots, 50 \mu \mathrm{M}$; and $\triangle \wedge, 100 \mu \mathrm{M}$. Values are means $\pm \mathrm{SD}$ (vertical bars). Values in control experiments are shown by the shaded area.

arginine, glucagon release from the control pancreas was rapidly reduced to the basal level; in contrast, glucagon release from the pancreas that had been perfused with $100 \mu \mathrm{M}$ W-7 remained virtually unchanged during $10 \mathrm{~min}$ following the withdrawal of both arginine and W-7.

Trifluoperazine at the concentration of $25 \mu \mathrm{M}$ and $50 \mu \mathrm{M}$ markedly inhibited the glucagon release induced by arginine with dosedependency. Trifluoperazine added to the perfusion medium together with $15 \mathrm{mM}$ arginine reduced the flow rate (data not shown), similarly as trifluoperazine administered together with glucose (Fig. 1B).

\section{DISCUSSION}

Evidence has accumulated that calmodulin plays an important role in various tissues, and the presence of calmodulin has been demonstrated in rat islets of Langerhans $(17,18)$. Calmodulin activates many enzymes in normal pancreatic islets $(14,16,17,18)$ and stimulates protein phosphorylation in hamstar insulinoma cells (8). Insulin release induced by glucose $(8,15)$, glyceraldehyde (8), potassium (15) and ouabain (15) in isolated islets is inhibited by trifluoperazine. These observations strongly suggest the possibility that $\mathrm{Ca}^{2+}$-dependent insulin release is 
regulated by a specific $\mathrm{Ca}^{2+}$-binding protein, i. e. calmodulin.

We have undertaken to examine this possibility using isolated perfused rat pancreas, which is expected to respond to drugs in a more physiological fashion than the isolated islets. We have compared the effects of trifluoperazine and $W-7$, a newly synthesized calmodulin inhibitor, on the endocrine pancreas.

Our results clearly demonstrate that W-7 and trifluoperazine inhibit glucose-induced insulin release in both the first and second phases of secretion in isolated perfused rat pancreas, and that W-7 is less potent than trifluoperazine in inhibiting the release of insulin and glucagon. These results lend a strong support to the assumption that $\mathrm{Ca}^{2+}$ stimulates the insulin release by its interaction with calmodulin, which somehow regulates the secretory processes in the pancreas.

Phenothiazine derivatives have been reported to act with a high affinity on the cell membrane and cytoskeleton, and cause striking morphological changes in cultured cells (13). In contrast to W-7, trifluoperazine reduced the flow rate in a dose-dependent manner, which may possibly be caused by the action of this agent on smooth muscles of the blood vessel. Trifluoperazine at $50 \mu \mathrm{M}$ reduced the flow rate to $25 \%$ of the initial level; but it reduced the insulin release more profoundly, i. e. to less than $10 \%$ of the control level (Fig. 1B). This implies that the reduction in the insulin release by trifluoperazine is attributable to a direct action of this agent on $B$ cells, though the influence arising from a lowered flow rate should also be taken into consideration.

The glucose-induced insulin release was suppressed very rapidly by introducing $\mathrm{W}-7$ in the perfusion medium; withdrawal of $\mathrm{W}-7$ caused an immediate over-secretion of insulin (Fig. 3), suggesting that the interaction between $\mathrm{W}-7$ and calmodulin is reversible. In contrast, trifluoperazine has been reported to bind to calmodulin either reversibly or irreversibly (19).

There have been conflicting observations with respect to the relation between calcium ions and glucagon release. In one experiment (10), glucagon release was increased when the calcium concentration was raised; in other experiment, however, the release was potentiated by the removal of calcium ions (9). To our knowledge, there has been no study where the relationship between calmodulin and glucagon release was analyzed. In our results, W-7 at a rather high concentration $(100 \mu \mathrm{M})$ significantly decreased the arginine-induced glucagon release (Fig. 4A). The glucagon release was suppressed also by trifluoperazine at concentrations effective in inhibiting the glucose-induced insulin release (Fig. 4B; cf. Fig. 1B). These observations support the possibility that calmodulin, together with calcium ions, enhances the glucagon release from the pancreas.

In summary, our present observations clearly indicate the involvement of calmodulin in the secretory process of insulin as well as glucagon in the pancreas. A study on the effect of calmodulin inhibitors on somatostation release from the pancreas is in progress.

We are grateful to Drs Hiroyoshi Hidaka and Nobuo Aoki for their generous gift of W-7. This study was supported in part by a grant-in-aid for Scientific Resarch from the Ministry of Education, Science and Culture, Japan (No. 56480354) and a grant from the Miura Memorial Foundation.

Received for publication 2 Jume 1981

\section{REFERENCES}

1. Cheung W. Y. (1970) Cyclic 3',5'-nucleotide phosphodiesterase: Demonstration of an activator. Biochem. Biophys. Res. Commun. 38, 533-538

2. Cheung W. Y. (1980) Calmodulin plays a pivotal role in cellular regulation. Science 207 , 19-27

3. Grodsky G. M., Batts A. A., Bennet L. L., VCella C., MCWilliams N. B. and Smith D. F. (1963) Effects of carbohydrates on secretion of insulin from isolated rat pancreas. Amer. J. Physiol. 205, 638-644

4. Hidaka H., asano M., Iwadare S., Matsumoto I., Totsuka T. and Aoki N. (1978) A novel vascular relaxing agent, $N$ (6-aminohexyl)-5-chloro-1-naphthalenesulfonamide which affects vascular smooth muscle actomyosin. J. Pharmacol. Exp. Therap. 207, $8-15$

5. Hidaka H., Naka M. and Yamaki T. (1979) Effect of novel specific myosin light chain kinase. Inhibitors on $\mathrm{Ca}^{2+}$-activated $\mathrm{Mg}^{2+}$-ATPase of chicken gizzard actomyosin. Biochem. Biophys. Res. Commtum. 90, 694-699

6. Kakiuchi S., Yamazaki R. and Nakajima $H$. (1970) Properties of a heat-stable phosphodiesterase activating factor isolated from brain extract. Studies on cyclic $33^{\prime}, 5^{\prime}$-nucleotide phosphodiesterase. II Proc. Japan Acad. 46, 587-592

7. Kobayashi R., Tawata M. and Hidaka H. (1979) $\mathrm{Ca}^{2+}$ regulated modulator protein interacting agents: Inhibition of $\mathrm{Ca}^{2+} \mathrm{Mg}^{2+}$ ATPase of human erythrocyte ghost. Bio- 
chem. Biophys. Res. Commun. 88, 1037-1045

8. Krausz Y., Wollheim C. B., Siegel E. and Sharp G. W. G. (1980) Possible role for calmodulin in insulin release: Studies with trifluoperazine in rat pancreatic islets. $J$. Clin. Invest. 66, 603-607

9. LeclercQ-Meyer V., Marchand J. and Malaisse W. J. (1973) The effect of calcium and magnesium on glucagon secretion. Endocinology 93, 1360-1370

10. Lundquist I., Fanska R. and Grodsky G. M. (1976) Direct calcium-stimulated release of glucagon from the isolated perfused rat pancreas and the effect of chemical sympathectomy. Endocrinology 98, 815-818

11. Means A. R. and Dedman J. R. (1980) Calmodulin-an intracellular calcium receptor. Nature 285, 73-77

12. Meyer W. L., Fischer E. H. and Krebs E. G. (1964) Activation of skeletal muscle phosphorylase $b$ kinase by $\mathrm{Ca}^{2+}$. Biochemistry 3,1033 1039

13. Osborn M. and Weber K. (1980) Damage of cellular function by trifluoperazine, a calmodulin-specific drug. Exp. Cell. Res. 130, 484-488

14. Pershadsingh H. A, McDaniel M. L., Landt M., Bry C. G., Lacy P. E. and McDonald
J. M. (1980) $\mathrm{Ca}^{2+}$-activated ATPase and ATPdependent calmodulin-stimulated $\mathrm{Ca}^{2+}$ transport in islet cell plasma membrane. Nature $\mathbf{2 8 8}$, 492-495

15. Schubart U. K., Erlichman J. and Leisher N. F. (1980) The role of calmodulin in the regulation protein phosphorylation and insulin release in hamster insulinoma cells. J. Biol. Chem. 255, 4120-4124

16. Sharp G. W. G., Wiedenkeller K. E., Kaelin D., Siegel E. G, and Wollheim C. B. (1980) Stimulation of adenylate cyclase by $\mathrm{Ca}^{2+}$ and calmodulin in rat islets of Langerhans. Diabetes 29, 74-77

17. Sugden M. C., Christie M. R. and Ashcroft S. J. H. (1979) Presence and possible role of calcium-dependent regulator (calmodulin) in rat islets of Langerhans. FEBS Letters 105, 95100

18. Valverde I., Vandermeers A., Anjaneyulu R. and Malaisse W. J. (1979) Calmodulin activation of adenylate cyclase in pancreatic islets. Science 206, 225-227

19. Weiss B., Prozialeck W. and Cimino M. (1980) Acute and chronic effects of psychoactive drugs on adrenergic receptors and calmodulin. $A d v$. Cyclic Nucleotide Res. 12, 213-225 